\title{
Effects of Summarization Tasks on Comprehension Monitoring of Science Texts in University Students with Elementary or Intermediate English Proficiency
}

\author{
Ángela Gómez and Anna Devís \\ Language and Literature Teaching, University of Valencia \\ Vicente SANJosé \\ Science Education, University of Valencia
}

Received: 15 February 2012 / Accepted: 25 March 2012

ISSN: $1697-7467$

\begin{abstract}
Two studies were conducted to improve Spanish university students' comprehension monitoring of macro-ideas when reading expository Science texts in English (L2). The first one evaluated the effects of using summarization tasks on comprehension monitoring compared to other reading-for-understanding tasks. A significant improvement of comprehension monitoring was obtained from the summarization tasks. Results in study 1 suggested study 2 aimed at instructing students on summarizing texts in L2. The instructional work had a single significant contribution to students' comprehension monitoring on the macro-structural level. English proficiency also explained a significant proportion of the variances.
\end{abstract}

Keywords: Comprehension Monitoring; Science Texts; Macrostructure; Summarization; EFL.

Efectos de las tareas de elaboración de resúmenes en el control de la comprensión de textos científicos en estudiantes universitarios con niveles de inglés elemental o intermedio

RESUMEN: Se desarrollan dos estudios para mejorar el control de la comprensión macrostructural en Universitarios españoles cuando leen textos expositivos de ciencias en inglés (L2). El primero evalúa el uso de tareas de resumen sobre el control de la comprensión, comparado con otras tareas de comprensión lectora. Realizar resúmenes produjo una mejora significativa en el control de la comprensión. Esto motivó el segundo estudio, dedicado a mejorar la elaboración de resúmenes en L2 por los estudiantes, mediante instrucción directa. La instrucción tuvo también una contribución significativa única sobre el control de la comprensión. El nivel de inglés tuvo efectos significativos también.

Palabras clave: Control de la Comprensión; Textos científicos; Macroestructura; Elaboración de Resúmenes. 


\section{INTRODUCTION}

In line with the guidelines of the European Higher Education Area (EHEA, http:// www.ehea.info/) Spanish universities are starting to demand from students a suitable level of English proficiency so that they will be able to communicate in daily life but also to develop and apply their knowledge in academic and labour contexts. Learning at university implies reading texts frequently, especially expository texts, because most of the information which students are provided with is throughout a written media. In this European context, having good reading comprehension and comprehension monitoring skills in L2 (especially in English), becomes necessary to access knowledge in different areas, for example that of Science.

Metacognitive reading skills have been proved to be related to deep understanding and academic success (Wang, Heartel and Walberg, 1993). In particular, it is well known that self-regulation strongly affects learning (Zimerman, 1990; Corno, 1986). Self-regulation is, in turn, related to the process of monitoring comprehension in reading tasks. 'Comprehension monitoring' (CM from here onwards) is the ability of a reader to be aware, while reading, whether a text is making sense or not (Brown, Bransford, Ferrara and Campione, 1983; Flavell, 1981).

Previous studies have analysed the level of comprehension shown by university students when they read expository texts about science topics in English (as L2), and have related it with their comprehension monitoring skills (Gómez, Solaz and Sanjosé, 2011). In these studies the 'Error Detection Paradigm' was assumed (Baker, 1985; Winograd and Johnston, 1982; Baker and Anderson, 1982). Students were asked to evaluate the comprehensibility of the texts and underline any contradictory or non-coherent idea, or any unknown word using a particular key code. Three short texts in English (200-220 words) as well as three texts in Spanish with the same structure and length were used. Each text included two embedded errors contradicting macro-ideas. Results obtained showed that students with elementary or intermediate levels of English showed poor CM on the macro-structural level compared to the one in their mother tongue. However, students showed good CM on the word (or lexical) level. Students' proficiency in L2 was expected to explain the levels of CM, but that factor only explained about 17 per cent of the individual differences (Gómez, 2011). These students had important obstacles to process textual macro-ideas. Thus, they could find important obstacles to understand academic texts in English or to develop their careers in the European labour market (Sanjosé, Solaz and Gómez, 2011).

There are two hypotheses at least to explain these poor results on the macrostructural CM when they read in English. The first hypothesis is to suppose that most students do not construct the text macro-structure properly. The second one is to suppose that these students construct the macrostructure, but they do not monitor it in an effective way. The most parsimonious hypothesis is the first one and we dedicate the present work to contrast it. Previous research proved that instruction in summarization skills significantly improved macro-structure building measures (Cordero-Ponce, 2000). Thus, present work focuses on CM measures under the assumption that summarization tasks will make students process text macrostructure better. 


\section{THEORETICAL FOUNDATIONS}

Understanding expository texts, as science texts, implies the construction of different mental representations (Kintsch, 1998). Constructing the text macrostructure is a previous, necessary condition to reach the Situation Model (Vidal-Abarca and Sanjosé, 1998), the highest level in text comprehension associated to deep understanding (Kintsch and van Dijk, 1978). Therefore, building the text macro-structure is crucial to reach deep understanding. The same three levels are implied in comprehension monitoring, as proved by Otero and Greasser (2001). Thus, we will distinguish CM on the Surface (lexical or 'word') level, on the Textbase level (micro and macro-structural) and also on the Situation Model level. At university, students have to read long expository texts and understanding the main ideas is one of the most important goals. Low levels of comprehension monitoring of macroideas could lead to low levels of understanding.

According to our previous hypothesis, the low level in comprehension monitoring exhibited by university students having elementary or intermediate English proficiency could be due to difficulties in constructing the text macrostructure. Some cognitive factors could substantiate our hypothesis. The first factor is the level of L2 cognitive processing. Non-bilingual students with a weak language command tend to process English texts at 'word' or local level and not at a global level (Segalowitz, 2000, Walczyk, 2000; Koda, 1990, 1996), using translation as the main strategy to extract meaning (Gómez, Solaz and Sanjosé, 2012). Therefore, their working memory could be loaded by many chunks, i.e., L2 words (or perhaps clauses) and also the corresponding L1 words (or clauses). Thus, there could not be enough cognitive resources to build macro-ideas from these elementary chunks (Walter, 2004, 2007; Yamashita, 2002; Tsai et al., 2010). Some other studies found similar problems (Stanley, 1984; Block, 1992) and recommended a shift in EFL teaching towards new approaches focusing on global or semantic processing of text information.

A second factor which would be implied in the hypothesis is the lack of appropriate cognitive goals when these students read texts in English. Few university students declared to frequently check whether or not the text content fitted the reader's goals or to analyse and evaluate the text information with a deep scrutiny (Gómez, Solaz and Sanjosé, 2012). Therefore, giving students a clear goal when they read for understanding seems to be a suitable educational purpose. The effect of specific proposed tasks on reading comprehension in EFL has been investigated before (Khajavi and Ketabi, 2012; Gordon and Hanauer, 1995).

Using summarization tasks in L2 reading seems to account for the two previous factors. Summaries are related to macro-structure elaboration because they focus on global coherence among the text main ideas and not on details (Golden, Haslett and Gauntt, 1988). Garner (1982) found that good summarizers were able to integrate different text main ideas into a coherent whole and to let apart irrelevant information. Reder and Anderson $(1980,1982)$ claimed that summaries were better for learning from texts than other tasks dealing with details in the text. Therefore summaries could help students to go beyond the word level and deal with long information units of meaning in L2. Moreover, reading-to-summarize is an appropriate reading goal for less skilled L2 learners to keep in mind. 


\subsection{Goals and Hypotheses}

Taking into account the above theoretical foundations and assuming that students' poor level of $\mathrm{CM}$ in English and thus, the low understanding of English text main ideas could be due to processing obstacles in building the text macro-structure, we formulate the next hypotheses:

1.- Giving the students a specific reading goal related to summarization of expository texts will improve students' $\mathrm{CM}$ on the macro-structural level, compared to other usual 'comprehension' reading conditions. In this work we expected that readingto-summarize would improve students macro-level processing compared to other reading-to-understand tasks and thus, would improve their comprehension monitoring of macro-ideas (Study 1).

2.- The better the students' summarization skills, the better the macro-structure construction and thus, the higher the comprehension monitoring on the macrostructural level. Hence, a specific instructional procedure aimed at enhancing students' ability to elaborate summaries from science expository texts will give a single contribution to the improvement of the students' comprehension monitoring on the macro-structural level. Cordero-Ponce (2000) obtained significant improvement in students' ability to discriminate main ideas from irrelevant or extraneous ideas by direct instruction. Thus we expected direct instruction on summarization will improve comprehension monitoring of main-ideas too (Study 2).

Corbeil (2000) studied L1-L2 differences in summarization skills and found effects of L2 proficiency in some of these skills. Hence, we expected students' English proficiency to be a significant causal factor, as found in previous studies.

\section{Study 1: effects of a SUMmarization tASK ON THE PROCESSing of EFL SCIENCE TEXTS}

\subsection{Method}

\subsubsection{Sample}

Sixty-one male and female Spanish university students participated in this study. They belonged to two intact groups at a Teacher Training faculty from a big city. Using the Oxford Online Placement Test (OOPT) (http:// www.oxfordenglishtesting.com ; Purpura, 2010; Pollit, 2009) these students were level-graded in English proficiency according to the Common European Framework of Reference for Languages (CERFL; Council of Europe, 2001). We only obtained the English proficiency level of fifty-three participants. A percentage of $18 \%$ of these subjects were in the A1 level, $31 \%$ in the A2, $43 \%$ in the B1 and only $8 \%$ were in the B2 level. 


\subsubsection{Design, Materials and Measurements}

In order to evaluate the effect of the task on reading comprehension and on macrostructural monitoring, we proposed students two different reading tasks and then we compared them (repeated measures design).

In the first task (the 'assessing the comprehensibility' task), we used two short texts in English (200-220 words) about general science topics ('Cloning' and 'Climate Change'; see Appendix), each of them including two embedded errors which contradicted macroideas. This is a usual task to assess comprehension monitoring according to the Error Detection Paradigm (Baker, 1985; Winograd and Johnston, 1982; Baker and Anderson, 1982). Students were asked to evaluate the comprehensibility of the texts and underline any contradictory or non-coherent idea or any unknown word using a particular key code. We expected good comprehenders would detect and underline the contradictions.

In the second task (the 'assessing the summary' task) we prepared two different summaries from two different expository texts about general science topics (see Appendix), and then modified them to include not only the main ideas from each text but also secondary ideas, lists of examples and extraneous ideas not mentioned in the texts. Finally, we modified two of the text main ideas in each summary to include macro-errors in order to obtain a second measure of students' comprehension monitoring on the macro-structural level. These embedded errors produced explicit contradictions with two textual main ideas. We asked students to assess the suitability of each idea included in these modified summaries using a particular key code. Students' had to codify ideas they thought were not appropriate for the summaries of the texts and also to explain the reason why (in L1 to avoid interferences from writing difficulties), in a blank space below each provided modified summary. In both tasks, the measure was the mean number of errors detected per person and per text. Finally, English proficiency was considered as an explaining factor in the analyses.

\subsection{Results}

In the 'assessing the comprehensibility' task the mean value was $0.49(\mathrm{SD}=0.67)$ out of 2 errors detected per subject and per text. In the 'assessing the summary' task the mean value was $1.05(\mathrm{SD}=0.76)$ errors detected per subject and per text. We performed a simple paired-t-test for these two measures and obtained significant effects from the task factor $(\mathrm{t}(60)=5.540 ; \mathrm{p}<.001)$. The effect size was large $\left(\eta^{2}=.34\right)$.

Next, we introduced the English proficiency as a between-subjects factor (four levels) together with the task as the within-subjects factor (two levels) and performed a '2X4' repeated measures ANOVA. When the English proficiency level was considered, it produced a significant main effect with a large effect size $\left(F(3,49)=5.814 ; \mathrm{p}=.002 ; \eta^{2}=.26\right)$. However, the task effect did not disappear and a large effect size remained $(F(1,49)=9.532$; $\left.\mathrm{p}=.003 ; \eta^{2}=.16\right)$. There was not significant interaction $(\mathrm{p}>.10)$ between the two factors.

\subsection{Discussion}

Compared to the 'assessing the comprehensibility' task, the 'assessing the summary' task seemed to stimulate students' awareness to control their understanding of text main 
ideas. This effect could be due to the need of checking the text again and again in order to judge the suitability of each idea included in the proposed summaries. This goal makes students monitor their comprehension in a more efficient way than the simply reading for understanding.

Therefore, summarization appears as an appropriate task to work in the classroom with the purpose of stimulating students without an advanced English proficiency level to change their information processing when reading academic texts. Summaries have been used in L2 to foster and to assess reading comprehension long time ago (Kozminsky and Graetz, 1986; Johns and Mayers, 1990).

These results encouraged us to design an experimental instruction based on summary elaboration. We evaluated its contribution to improve students' comprehension monitoring on the macro-structural level and thus, their understanding of macro-ideas. We took into account the contribution made by the summarization task alone, and isolated the single contribution from the experimental instruction.

\section{Study 2: an instructional design to improve STUdents' ability to CONSTRUCT THE TEXT MACRO-STRUCTURE}

\subsection{Method}

\subsubsection{Sample}

Forty-nine male and female Spanish students in their first year at university (typical age 18-21) participated in this pilot study 2 . None participated in study 1 . They belonged to two intact groups at the same Teacher Training Faculty of study 1. They were enrolled in English Language for Teachers, a subject taught in the first year of the degree combining language knowledge (on the B1 level) with teaching skills. The instructional tasks proposed were inserted in the usual lessons in order to develop students' reading competence.

\subsubsection{Design, Materials and Measurements}

This was a one-group study with a Pretest-Intervention-Posttest structure.

In the pretest phase, we used two different tasks. The first one was the 'assessing the comprehensibility task' used in study 1 and the measure was the mean number of detected macro-errors per subject and per text. The second one was a usual summary task to be aware of the students' aptitude in this particular task. Students had to write a summary for each of the two texts provided. These two texts dealt with general science topics ('How rainbows are formed' and 'Biomass: the growing energy resource'), and they were of comparable length (500-540 words) and structure (description, causation or problem/solution). Texts had to be long enough to include not only the important ideas in the topic but also secondary ideas, details and examples. Therefore, identifying main ideas and discriminating them from other less important ideas would imply some cognitive 
and metacognitive effort. We asked students to write their summaries in Spanish (L1). In this way we tried to avoid the influence of writing competence on reading comprehension, and also the «copy-and-paste» strategy, i.e. the direct copying of sentences from the text into the summaries.

As summarization is not a well-defined task two different experts elaborated summaries for each of the texts used in the pre-tests and the posttest. Discrepancies were solved by discussion and a final set of main ideas of each text was obtained. This set of main ideas was used to assess students in the pretest and the posttest. The number of main ideas included by each participant in his/her summaries was compared to the number of main ideas included by these experts in their summaries. So, we obtained the mean value of main ideas per person and per text divided by the total possible number of main ideas according to the experts' criteria.

In the instructional phase, four texts of similar length ('How rainbows are formed' and 'Biomass: the growing energy resource', 'Lightning' and 'Earth's sunscreen: the ozone layer') were used to teach students how to elaborate good summaries and so to stimulate students' elaboration of text macro-structure.

The reading difficulty of the texts was tested using a two-way protocol. First, the Flesch Reading Ease Readability Formula (2011; Flesch, 1948) was used to set the difficulty scores of ten initial texts. Next, an expert level-graded each text. Although most students had low English proficiency levels, we selected six texts in a level range between B1-B2 because this is the English proficiency students should reach in the course. Flesch's score of these texts were between 40 and 70. Therefore, in the testing as well as in each instructional session, we used an easy text (B1; Flesch's score $=60-70)$ and a difficult text (B2; Flesch's score $=40-50)$.

The posttest task was the same 'assessing the summary task' used in study 1. This task met two concurrent conditions: first, it was coherent with the instructional work, i.e., based on summarization and main ideas identification; second, it provided us with a $\mathrm{CM}$ measure at macro-structural level.

As in study 1 we also control the participants' English proficiency. We obtained this measure from only forty-four students in the sample.

\subsubsection{Instructional Procedure}

The instructional phase took a total time of four hours. In the first training session an outline illustrating the main steps to write a good summary was provided to students (Appendix). It was an adaptation to L2 of Sánchez's (1993) programme of reading comprehension instruction. Other programmes had been used with the same goal (Cordero-Ponce, 2000). As our instruction had to deal with English as L2 and participants had low English proficiency levels, we introduced some minor changes in the reading comprehension programme in order to meet students' particular difficulties. The instructional protocol followed the following steps:

(A) Global reading: Identification of the text subject matter: students skimmed the text during several minutes and try to answer the question: what is the text about? Before going on, a general agreement about the topic was reached. Then we worked paragraph after paragraph and we followed the following procedure: 
(B) Underlining of unknown words: after this initial underlining, the instructor encouraged students to circle only the words which they considered absolutely 'essential' to understand the meaning of the whole paragraph (not the sentence). Special emphasis was put on this step. Then, they could only ask for the meaning of the circled words. In the first session, most participants exhibited a strong resistance to skip unknown words and they stopped at every unknown word they found. This behaviour supports our previous hypothesis: low proficiency students use a low level (word level) processing when they read in English.

Throughout the two first hours students noticed that most words they had circled where not essential for them to understand the main idea in the paragraph. Significantly, in the third hour no word was circled as 'essential' and no one stopped at unknown words, so students started to change their focus from wordby-word processing to macro-ideas processing. Nonetheless, the instructor helped students to work out the meaning of some of the underlined words using the context (translation into L1 was never used in the instruction) at the end of the instructional work.

(C) Identifying the text structure/s: students should try to identify the structure/s of the paragraph: we only used description, causation or problem-solution in instructional texts so students had no severe problems in this step.

(D) Identifying the main ideas of each paragraph discriminating between the main and secondary ideas. Students should write using their own words the most important idea/s of each paragraph. Before performing this subtask the instructor helped students discriminate a main idea from other kinds of text ideas such as: secondary ideas (sentences developing other previous ideas or giving extra details); ideas coming from one's previous knowledge on the topic but not present in the text; lists of terms which can be substituted by a superordinate term; and examples. Main ideas are textual or elaborated sentences characterized as those which: 1) refer to the topic of the text (identified before) and not to other secondary topics (Relevance); 2) define, describe, explain and talk about consequences (natural or social) related to the topic of the text (Organization and structure of expository -scientific-, information); for instance, in the text Lightning the main idea 'Lightning is a bright flash of electric current produced by a thunderstorm' is a definition and a description of the main topic of the text; 3) use general terms and group together particular cases, lists of characteristics or consequences, justifications, etc. (the 'Generalization' macro-operator); 4) contain the information necessary to understand other parts of the text (global Coherence); for instance, the text Lightning contains the idea 'The origin of lightning is the electrification of the clouds', which is necessary to understand other parts of the text and it also helps understanding the reason why lightning is produced; 5) do not include examples and details (the 'Deletion' macro-operator).

Moreover, students were instructed on how to write a main idea: 1) Main ideas can, sometimes, be drawn from the text literally (the 'Selection' macro-operator); 2) But most of the times several sentences of the text should be taken into 
account to write a main idea in a different non-literal way, i.e., more briefly and more general, without details (the 'Construction' macro-operator); for example, 'The most dangerous type of lightning is the cloud-to-ground one because it strikes tall pointed objects and can cause death, fire and property damage' is a main idea, from the text Lightning, re-written in a non-literal way from several sentences of two different paragraphs.

(E) Relationship among the different paragraphs: the main ideas of each paragraph have to be related in order to build a coherent text representation. Before starting with a new paragraph, students should remember the main ideas of the previous paragraphs and link them with the new ones. We did not use graphics to visualise the relationship among the text main ideas, but the links were constructed out loud.

(F) Summary writing: students try to write a summary with all the main ideas they have extracted from the text.

(G) Summary polishing: after writing the summary, students should re-write it and make the necessary adjustments so that it becomes a coherent text. Students were stimulated to improve their summary reordering the ideas, paraphrasing, using cohesive devices such as pronouns and connecting words, avoiding redundancies and getting rid of repetitive information, using superordinate terms instead of lists of terms, etc.

In the first two instructional hours students practiced using the outline above with the two texts used in the pretest summary task ('How rainbows are formed' and 'Biomass: the growing energy resource'). In the third and fourth hours, the same procedure was followed with two new texts ('Lightning' and 'Earth's sunscreen: the ozone layer') so that students had more practice.

Throughout the teaching sessions the general instructional procedure and further explanations were given in Spanish (L1) to foster students' understanding.

\subsection{Results}

Participants' ability to elaborate summaries was moderate in the pretest. They included a mean proportion of $0.53(\mathrm{SD}=0.17)$ main ideas in their summaries (the proportion is computed with respect to the total possible main ideas according to an experts' criterion). Therefore, instructional work specifically addressed to improve this ability makes sense.

However, our purpose was to analyse whether or not the understanding and comprehension monitoring on the macro-structural level improved after instruction. In

\footnotetext{
${ }^{1}$ As the ideas containing macro-errors in the posttest summaries were also important text main ideas, the summarization measure includes the control-monitoring measure. Thus, in order to avoid overlapping between the two measures and spurious common variance, this Spearman's rho has been calculated excluding the main ideas including the macro-errors in the summarization measure
} 
this study 2, students obtained clearly lower values in the 'assessing the comprehensibility task' than students in study 1. They detected a mean value of $0.27(\mathrm{SD}=0.38)$ out of 2 errors per subject and per text. This measure was significantly correlated with the proportion of main ideas included in the pre-test summaries (Spearman's $r=.316 ; p=.029$ ), i.e. the comprehension monitoring measure correlated with the summarization measure (understanding measure).

As in Study 1, students in Study 2 improved their comprehension monitoring in the 'assessing the summary' task after the instructional work, compared to the 'assessing the comprehensibility' task before the instruction. The mean value was $1.14(\mathrm{SD}=0.66)$ out of 2 errors per subject and per text. Again this measure was significantly correlated with the number of main ideas correctly considered suitable in the posttest summaries ( $\mathrm{r}=$ $\left..363^{1} ; \mathrm{p}<.011\right)$.

Paired t-test showed significant differences between the pre-test and the posttest comprehension monitoring measures with a large effect size $\left(\mathrm{t}(48)=7.965 ; \mathrm{p}<.001 ; \eta^{2}=.57\right)$ as in study 1. When the English proficiency level was considered, results obtained in Study 1 were also replicated with large effect sizes. The main effect from this factor was significant $\left(\mathrm{F}(3,40)=4.606 ; \mathrm{p}=.007 ; \eta^{2}=.26\right)$ and again the task effect remained significant $\left(\mathrm{F}(1,40)=44.044 ; \mathrm{p}<.001 ; \eta^{2}=.52\right)$ without interaction effect between the within and the between-subjects factors $(\mathrm{p}>.20)$.

However, we had to evaluate the extent to which the instructional work provided a single contribution different from the 'task effect' found in study 1 due to the differences between the performance in the 'assessing the summary task' compared to the one in the 'assessing the comprehensibility task'. In order to isolate the possible effect due to the instruction we used Study 1 as the 'control group' and compared it with the instructed group of students. Next, we performed a mixed 2 X 2 ANOVA with the two error detection measures as the within-subjects factor (the 'Task' factor) and the two groups as the between-subjects factor (the 'Group' factor).

Again, there were significant differences between the two comprehension measures 'assessing the comprehensibility' and 'assessing the summary' $(F(1,108)=91.733 ; p<.001)$ with a large effect size $\left(\eta^{2}=.46\right)$. And the most important, there was also a significant interaction between this factor and the Group factor with a small to moderate effect size $\left(\mathrm{F}(1,108)=4.342 ; \mathrm{p}=.40 ; \eta^{2}=.04\right)$, indicating that the differences above were not similar in both groups of students.

When the English proficiency level was also considered as a second betweensubject factor, the important effects remained. There were significant differences between the two comprehension measures with a large effect size $\left(F(1,89)=45.959 ; p<.001 ; \eta^{2}=\right.$ .34), and also a significant Task $\mathrm{X}$ Group interaction effect with a moderate effect size $\left(\mathrm{F}(1,89)=5.461 ; \mathrm{p}=.022 ; \eta^{2}=.06\right)$. The main effect of the English proficiency level was also significant and the effect size was large $\left(F(3,89)=6.359 ; p=.001 ; \eta^{2}=0.18\right)$. The estimated mean values for the number of errors detected in both measures increased with the proficiency level: 0.41 (A1); 0.62 (A2); 0.83 (B1) and 1.21 (B2).

\subsection{Discussion}

The significant contribution from the summarization task to improve students' comprehension monitoring on the macro-level found in Study 1, was replicated in Study 
2. In addition, the experimental instruction addressed to improve students' ability to detect textual main ideas and to elaborate appropriate summaries in science texts, produced a significant single contribution to the students' understanding of macro-ideas. Therefore, the instructional design received support from the data although their effect size was only moderate. The English proficiency levels explained significant proportions of the variance in all the analyses performed but the aforementioned significant effects did not vanish.

\section{Conclusions}

Previous research showed important obstacles in macro-structural processing in university students having elementary or intermediate English proficiency. According to our hypothesis, the observed difficulties in building the text macro-structure could be attributed to students' local level (word level) processing of English texts (Segalowitz, 2000; Walczyk, 2000; Koda, 1990, 1996). Their low English proficiency levels would make them focus on word meaning and translation from L2 to L1 (Gómez, Solaz and Sanjosé, 2012) causing a cognitive overload in their working memory. This load would not let enough free cognitive resources for macro-operators to build the macrostructure.

Two studies were conducted to evaluate two possibilities to induce a change in the students' processing of text macro-ideas. The first one aimed at evaluating the effects of the reading task on the understanding of macro-ideas in science texts, as measured by the detection of embedded errors in main ideas. Assessing a provided summary obtained significant better results than assessing the comprehensibility of a text. This orientated the second study. We found that assessing the suitability of summaries enhanced the use of the comprehension monitoring strategy on the macro-structural level, compared to assessing the comprehensibility of texts. This result is in agreement with other previous studies reporting the impact of different reading tasks on information processing (Kintsch, 1994; McNamara and Kintsch, 1996; Oded and Walters, 2001).

In the second study we evaluated an experimental direct instruction addressed to improve the students' ability to elaborate good summaries from expository texts. We assumed that helping students to build the text macrostructure would help them improve their comprehension of macro-ideas. In line with Block's (1992) and Stanley's (1984) suggestions we tried to shift the way Spanish students usually processed English texts from the word (or surface) level to the macro-structural level. The instructional procedure was based on summarization because this task implies building macro-ideas as well as discriminating them from other less important ideas. In fact, the significant improvement obtained in Study 1 oriented the use of summarization tasks instead of other reading comprehension tasks.

We adapted Sánchez's (1993) programme of reading comprehension instruction in L1 to L2 with some changes. One of the adaptations of Sánchez's programme consisted in underlining the unknown words and circling the ones they considered absolutely 'essential' to understand the meaning of the whole paragraph. In the first session, most participants stopped at every unknown word they found because they thought they were an obstacle for them to understand the text and they felt overwhelmed. This behaviour supports our previous hypothesis that students with low language proficiency tend to process texts 
on word level when they read in English. Furthermore, in the following sessions students realized that most words they had circled where not essential for them to understand the text main ideas and no one stopped at unknown words. So thanks to the training programme students initiated a change in their way of approaching texts in English from word-by-word processing to macro-ideas processing.

The effect of the instructional work in the classroom was significant and supposed a single significant contribution to the improvement of students' reading comprehension on the macro-level, in line with Cordero-Ponce's work (2000). Therefore, in studies 1 and 2 we obtained two different significant effects, a 'task effect' and an 'instructional effect' on the CM measures.

We expected that, as in a previous exploratory study (Gómez, 2011), the understanding on the macrostructural level will also depend on their L2 proficiency. In both studies this expectation was confirmed but this factor did not eliminate the other significant effects. A previous study from Sotoudehnama and Azimfar (2011) reported that their high proficiency students declared to use more reading strategies than low proficiency students, no matter the difficulty of the proposed task. In our studies participants having the higher English proficiency levels also scored higher in the comprehension monitoring strategy use than the lower proficiency participants, in both proposed tasks.

These studies were exploratory, specially study 2. The instructional design used has to be completed and improved in several ways. First, we should take other measures of reading comprehension apart from the ones of comprehension monitoring. Second, the measures we obtained in Study 2 were administered in a short time after the last session. A delayed measure is needed to prove the changes induced in text processing are stable. Third, we had to use different text structures to make the procedure more general and functional. Fourth, some instructional work specifically addressed to establish global coherence among text main ideas seem to be desirable to help students go beyond the Text-Base mental representation (with the micro and macro-structural levels) and to build the Situation Model, the higher mental representation associated to deep understanding. Finally, we did not design specific instructional tasks to work on macro-structural comprehension monitoring or to develop students' metacognitive awareness explicitly. However, students' metacognitive reading strategies have to be developed, in particular comprehension monitoring. This skill is important when global coherence has to be constructed because it influences the success in detecting contradictions, inconsistencies or coherence breakdowns in the discourse. We are now working on these improvements.

\section{BibLIOGRAPHICAL REFERENCES}

Baker, L. and Anderson, R. I. (1982). «Effects of inconsistent information on text processing: evidence for comprehension monitoring», in Reading Research Quarterly, 17: 281-294.

Baker, L. (1985). «How do we know when we don't understand? Standards for evaluating text comprehension», in D.L. Forrest-Pressley, G. E. Mackinnon \& T.G. Waller (Eds.), Metacognition, Cognition and Human Performance. Orlando, FL: Academic Press, 155205. 
Block, E. (1992). «See how they read: Comprehension monitoring of L1 and L2 readers», in TESOL Quarterly, 26, 2: 319-343.

Brown, A., Bransford, R., Ferrara, R. and Campione, J. (1983). «Learning, Remembering, and Understanding», in P. Mussen (Ed), Handbook of Child Psychology: Cognitive development. New York: John Wiley and Sons, 515-629.

Corbeil, G. (2000). «Exploring the Effects of First- and Second-Language Proficiency on Summarizing in French as a Second Language», in Canadian Journal of Applied Linguistics, 2, 1-2: 3562.

Cordero-Ponce, W.L. (2000). «Summarization Instruction: Effects on Foreign Language Comprehension and Summarization of Expository Texts», in Reading Research and Instruction, 39, 4: 329350 .

Council of Europe (2001). Common European Framework of Reference for Languages: Learning, Teaching, Assessment. Cambridge (U.K.): Cambridge University Press.

Corno, L. (1986). «The metacognitive control components of self-regulated learning», in Contemporary Educational Psychology, 11: 333-346.

Flavell, J.H. (1981). «Cognitive monitoring», in W. P. Dickson (Ed.), Children's oral communication skills. New York: Academic Press, 35 - 60.

Flesch, R. (1948). «A new readability yardstick», in Journal of Applied Linguistics, 32: 221-223.

Garner, R. (1982). «Efficient text summarization: costs and benefits», in Journal of Educational Research 75: 275-279.

Golden, J., Haslett, B. and Gauntt, H. (1988). «Structure and content in Eighth-Graders’ summary essays», in Discourse Processes, 11: 139-162.

Gómez, A. (2011). «Análisis del control de la comprensión en primera lengua (español) y en lengua extranjera (inglés): Un estudio experimental con estudiantes universitarios españoles con niveles elementales e intermedios de inglés». Memoria final del Máster en Investigación en Didácticas Específicas. Universitat de València.

Gómez, A. Solaz, J.J., and Sanjosé, V. (2011). «Failures to process science macro-ideas in English at University: an experimental study with Spanish undergraduates», in proceedings of the International Conference of Education, Research and Innovation (ICERI). $14^{\text {th }}-16^{\text {th }}$ November, Madrid.

Gómez, A., Solaz, J.J. and Sanjosé, V. (2012). «Competencia en Lengua Inglesa de Estudiantes Universitarios Españoles en el contexto del EEES: nivel de dominio Lingüístico, Estrategias Metacognitivas y Hábitos Lectores», in Revista de Educación, in Press.

Gordon, C.M. and Hanauer, D. (1995). «The interaction between task and meaning construction in EFL reading comprehension tests», in TESOL Quarterly 29: 299-324.

Johns, A.M. and Mayes, P. (1990). "An analysis of summary protocols of university ESL students», in Applied Linguistics, 11: 253-272.

Khajavi, Y. and Ketabi, S (2012). «Influencing EFL learners' reading comprehension and selfefficacy beliefs: The effect of concept mapping strategy», in Porta Linguarum, 17: 9-27.

Kintsch, W., 1994. «Text comprehension, memory, and learning», in American Psychologist 49: 292-303.

Kintsch, W. and van Dijk, T.A. (1978). «Towards a model of text comprehension and production», in Psychological Review, 85: 363-394.

Kintsch, W. (1998). Comprehension: A paradigm for cognition. Cambridge: Cambridge University Press.

Koda, K. (1990). «The use of L1 reading strategies in L2 reading», in Studies in Second Language Acquisition. 12: 293-410.

Koda, K. (1996). «FL word recognition research: a critical review», in Modern Language Journal, 80: $450-460$. 
Kozminsky, E. and Graetz, N. (1986). «First vs. second language comprehension: some evidence from text summarizing», in Journal of Research in Reading 9: 3-21.

McNamara, D.S. and Kintsch, W. (1996). «Learning from texts: effects of prior knowledge and text coherence», in Discourse Processes 22: 247-288.

Oded, B. and Walters, J. (2001). «Deeper processing for better EFL reading comprehension», in System, 29: 357-370.

Otero, J. and Graesser, A.C. (2001). «PREG: Elements of a model of question asking», in Cognition and Instruction, 19: 143-175.

Pollitt, A. (2009). «The OOPT: The meaning of OOPT scores», available from: http:// www.oxfordenglishtesting.com, accessed October 2010.

Purpura, J.E. (2010). «The OOPT: What does it measure and how? Language focus: Use of English and listening ability», available from: http://www.oxfordenglishtesting.com, accessed October 2010.

Reder, L.M. and Anderson, J.R. (1980). «A comparison of texts and their summaries: memorial consequences», in Journal of Verbal Learning and Verbal Behavior 19: 121-134.

Reder, L.M. and Anderson, J.R. (1982). «Effects of spacing and embellishment on memory for the main points of a text», in Memory and Cognition 10: 97-102.

Sánchez, E. (1993). Los textos expositivos. Estrategias para mejorar su comprensión. Madrid: Santillana.

Sanjosé, V., Solaz, J.J. and Gómez, A. (2011). «Control de la comprensión durante la lectura de textos de ciencias en inglés. ¿Están preparados los estudiantes universitarios españoles para integrarse en el Espacio Europeo de Educación Superior?», in Didáctica de las Ciencias Experimentales y Sociales 25: 149-163.

Segalowitz, N. (2000). «Automaticity and attentional skill in fluent performance», in H. Riggenbach (Ed), Perspectives on Fluency. Ann Arbor. MI: University of Michigan Press, 200-219.

Sotoudehnama, E. and Azimfar, F. (2011). «The effect of presence versus absence of reading task and its difficulty level on reading strategies use», in Porta Linguarum, 16: 105-121.

Stanley, R.M. (1984).»The recognition of macrostructure: a pilot study», in Reading in a Foreign Language, 2: 156-168.

Tsai, Y-R., Ernst, C. and Talley, P.C. (2010). «L1 and L2 strategy use in reading comprehension of Chinese EFL readers", in Reading Psychology, 31, 1: 1-29.

Vidal-Abarca, E. and Sanjosé, V. (1998). «Levels of comprehension of scientific prose: the role of text variables», in Learning and Instruction, 8, 3: 215-233.

Walczyk, J.J. (2000). «The interplay between automatic and control processes in reading», in Reading Research Quarterly, 35: 554-566.

Wang, M.C., Haertel, G.D. and Walberg, H.J. (1993). «Toward a knowledge base for school learning» in Review of Educational Research, 63, 3: 249-294.

Walter, C. (2004). «Transfer of reading comprehension skills to L2 is linked to mental representations of text and to L2 working memory», in Applied Linguistics, 25, 3: 315-339.

Walter, C. (2007). «First- to Second-language reading comprehension: not transfer, but access», in International Journal of applied Linguistics, 17, 1: 14-37.

Winograd, P. and Johnston, P. (1982). "Comprehension monitoring and the Error Detection Paradigm», in Journal of Reading Behavior, 14, 1: 61-76.

Yamashita, J. (2002). «Mutual compensation between L1 reading ability and L2 language proficiency in L2 reading comprehension», in Journal of Research in Reading, 25, 1: 81-95.

Zimmerman, B.J. (1990). «Self-regulated learning and academic achievement: an overview», in Educational Psychologist, 25: 3-17.

http://www.readabilityformulas.com/flesch-reading-ease-readability-formula.php), accessed September 2011. 


\section{APPENDiX}

A.-One of the experimental texts to measure Comprehension Monitoring which was used in this study. Macro-errors have been underlined

Length: 220 words

Index of difficulty: 66.4 (Flesch Reading Ease Formula)

\section{The Arctic Sea Ice is Melting}

Greenhouse effect in the Earth is caused by heat-trapping gases like carbon dioxide in the atmosphere. An increase of the greenhouse effect will cause global warming and environmental changes. One of these changes is the reduction of the mass of sea ice floating on the Arctic Ocean.

Dr Julienne Stroeve is the author of a new study about the Arctic's ice surface. Warm waters entering the Arctic region combined with warming air temperatures are causing the destruction of the sea ice. Dr Stroeve found that since 1953 the area of sea ice in the Arctic has declined at an average rate of 7,8 per cent per decade. She compared the observed tendencies between 1953 and 2150 with the projections made by a group of experts on climate change. This study estimated the ice area is decreasing at an average rate of 2,5 per cent per decade in the same period. Summing up, sea ice on the Arctic Ocean is going up year-by-year. Climate experts may have underestimated the power of global warming from human-generated greenhouse gases. When the concentration of carbon dioxide grows up, the greenhouse effect becomes less important. If emissions of heat-trapping gases were not significantly decreased, the Arctic region could end up with no floating ice in a few decades.

B.-One of the modified summaries corresponding to Artificial Sweeteners text. The ideas containing the embedded macro-errors have been underlined here to help noticing. Instructions were written in Spanish and have been translated into English below. The source text in English has got 495 words, 4 paragraphs and a 40.6 level of reading difficulty according to the Flesch Reading ease Formula.

RESUMEN Y JUICIO (Subraya y Usa el código)

SUMMARY TO BE JUDGED (Underline and use the keycode)

Artificial sweeteners are substances used instead of sucrose. Because artificial sweeteners are many times sweeter than table sugar, greater amounts are needed to create the same level of sweetness. Saccharin is one of the most used artificial sweeteners. Its sweetness is 200 to 700 times sweeter than sucrose (table sugar). Experiments performed on rats found a relation between artificial sweeteners and cancer. Saccharine was included in the list of potential carcinogens. The FDA proposed to prohibit saccharine in human food and consumers strongly supported this decision. Later, carcinogenicity studies, mechanistic studies and human epidemiology studies did not demonstrate that artificial sweeteners produced cancer in humans. Saccharine was then excluded from the list of carcinogens. Nowadays, 
saccharin is considered one of the safest artificial sweeteners. Moreover, saccharin is the best sold product in many supermarkets.

REESCRIBE aquí debajo, en castellano o valenciano, las ideas que hayas subrayado con un « 2 » o con un « 3 », tal y como deberían quedar en el resumen, a tu juicio

REWRITE below, in your mother tongue, the ideas you have underlined and codified as ' 2 ' or ' 3 ', as, in your opinion, they should be written in the summary. 